Abstract P001 Table 1 Newly initiated patients on rituximab (1/10/2015 to 30/09/2020)

\begin{tabular}{|c|c|c|c|c|c|c|c|c|}
\hline \multirow[t]{2}{*}{ Time period } & \multirow[t]{2}{*}{ Total new patients $(\mathrm{n})$} & \multirow[t]{2}{*}{ Gender (\%) } & \multicolumn{3}{|c|}{ Serum virology pre-initiation screening } & \multicolumn{3}{|c|}{ Positive virology detected in patients screened } \\
\hline & & & HBSAg & HBcAb & HCV Ab & HBSAg & HBcAb & HCV Ab \\
\hline $1 / 10 / 2015-30 / 09 / 2016$ & 161 & $\begin{array}{l}M-59 \\
F-41\end{array}$ & $\begin{array}{l}62 \% \\
(n=100)\end{array}$ & $\begin{array}{l}59 \% \\
(n=95)\end{array}$ & $\begin{array}{l}89 \% \\
(n=144)\end{array}$ & $0 \%$ & $\begin{array}{l}2 \% \\
(n=2)\end{array}$ & $0 \%$ \\
\hline $1 / 10 / 2016-30 / 09 / 2017$ & 121 & $\begin{array}{l}M-48 \\
F-52\end{array}$ & $\begin{array}{l}73 \% \\
(n=88)\end{array}$ & $\begin{array}{l}62 \% \\
(n=75)\end{array}$ & $\begin{array}{l}92 \% \\
(n=111)\end{array}$ & $0 \%$ & $\begin{array}{l}4 \% \\
(n=3)\end{array}$ & $\begin{array}{l}<1 \% \\
(n=1)\end{array}$ \\
\hline $1 / 10 / 2017-30 / 09 / 2018$ & 103 & $\begin{array}{l}M-37 \\
F-63\end{array}$ & $\begin{array}{l}92 \% \\
(n=95)\end{array}$ & $\begin{array}{l}73 \% \\
(n=75)\end{array}$ & $\begin{array}{l}96 \% \\
(n=99)\end{array}$ & $0 \%$ & $0 \%$ & 0 \\
\hline $1 / 10 / 2018-30 / 09 / 2019$ & 115 & $\begin{array}{l}M-47 \\
F-53\end{array}$ & $\begin{array}{l}94 \% \\
(n=108)\end{array}$ & $\begin{array}{l}83 \% \\
(n=96)\end{array}$ & $\begin{array}{l}96 \% \\
(n=110)\end{array}$ & $\begin{array}{l}<1 \% \\
(n=1)\end{array}$ & $\begin{array}{l}7 \% \\
(n=7)\end{array}$ & $\begin{array}{l}<1 \% \\
(n=1)\end{array}$ \\
\hline $1 / 10 / 2019-30 / 09 / 2020$ & 106 & $\begin{array}{l}M-46 \\
F-54\end{array}$ & $\begin{array}{l}94 \% \\
(n=100)\end{array}$ & $\begin{array}{l}84 \% \\
(n=89)\end{array}$ & $\begin{array}{l}95 \% \\
(n=101)\end{array}$ & $0 \%$ & $\begin{array}{l}7 \% \\
(n=6)\end{array}$ & $\begin{array}{l}1 \% \\
(n=1)\end{array}$ \\
\hline
\end{tabular}

prophylaxis after being referred to the hepatobiliary service. There were no cases of hepatitis B reactivation in the study period.

Conclusions A significant number of patients are not being screened for Hepatitis B core antibodies, despite local education programmes in 2016 and 2018. Low background rates of $\mathrm{HBV}$ in the local community may account for low levels of previous and current HBV infections. Education of prescribers, modifications to the initiation pharmacy checklists and simplification of computer request process should help to improve Hepatitis B screening in our patients and avoid potentially life threatening reactivation.

\section{P002 THE ROLE OF TRANSIENT ELASTOGRAPHY AND PLATELETS COUNT IN PREDICTING PATIENTS WHO CAN AVOID OESOPHAGOGASTRODUODENOSCOPY FOR VARICEAL SCREENING. VALIDATING THE BAVENO VI CRITERIA - EXPERIENCE FROM A DISTRICT GENERAL HOSPITAL (DGH) FOR A COHORT OF PATIENTS WITH HETEROGONOUS AETIOLOGY OF CHRONIC LIVER DISEASE}

Luis Neto Pereira*, Omar Farouk, Zaw Aung, Dipal Juthani, Martin Mcgrath, Sambit Sen, Pooja Khanna. Luton and Dunstable Hospital, Luton, UK

\subsection{6/gutjnl-2021-BASL.12}

Background Variceal haemorrhage is a major cause of morbidity and mortality in patients with chronic liver disease (CLD). Oesophagogastroduodenoscopy (OGD) is the gold standard for variceal screening. Baveno VI guidelines recommend that in patients with CLD a Liver Stiffness measurement (LSM) $<10 \mathrm{kPa}$ may rule out compensated CLD and also recommend that patients with $\mathrm{LSM}<20 \mathrm{kPa}$ and a platelet count (PLT) of $>150000$ are at low risk of clinically significant varices (CSV) and may safely omit OGD for variceal surveillance.

Objectives Examine the utility of these cut offs in a cohort of patient with heterogeneous aetiology of CLD at a District General Hospital (DGH).

Methods We interrogated electronic Transient Elastography (TE) records to identify patients who underwent TE between $06 / 2018$ and $06 / 2019$. For those with LSM >10kPa, electronic case note review was performed to identify those who underwent OGD within 12 months of their TE and had PLT available. Data were collected for endoscopic findings, PLT, aetiology of CLD and outcomes (variceal bleeding and mortality). CSV were defined as oesophageal varices (OV) described as grade 2 or above. We defined 'Baveno positive category' as patients with either $\mathrm{LSM} \geq 20 \mathrm{kPa}$ and/or PLT $\leq 150000$, 'Baveno negative category' were those with both LSM $<20 \mathrm{kPa}$ and PLT $>150000$. Sensitivity, specificity, positive and negative predictive values (PPV and NPV) for the detection of CSV were calculated.

Results 1075 patients underwent TE.

229/1075 patients had LSM $>10 \mathrm{kPa}$ of whom $124 \mathrm{had}$ undergone OGD within 12 months and PLT available.

$45 / 124$ patients who underwent OGD had varices of any grade and 27/124 (21.7\%) had CSV.

$36 / 124$ patients had LSM $<20 \mathrm{kPa}$ and PLT $>150000$ of whom only 1 had CSV with a high NPV at 97.2\%.

Overall sensitivity and specificity were $96.3 \%$ and $36.1 \%$ respectively.

$14 / 229(6.1 \%)$ experienced variceal bleed; all of them were in Baveno positive category.

$22 / 229(9.6 \%)$ of patients died. Mortality was significantly higher among patients in Baveno positive category. Only 1 patient in Baveno negative category died $(0.43 \%)$, cause of death was not related to variceal bleed or hepatic decompensation.

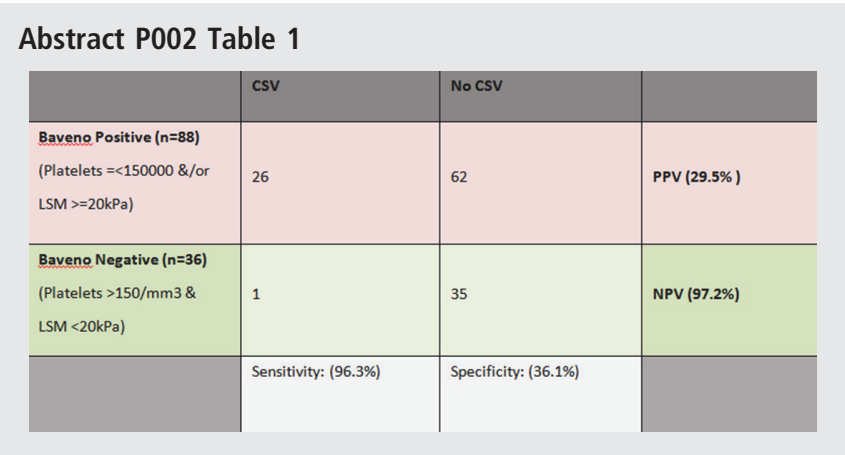

Conclusion Our results show that in DGH cohort of heterogeneous aetiology of CLD, the Baveeno VI criteria can be safely used to avoid endoscopic screening for CSV. Mortality rate was significantly lower in patients in Baveno negative category and none experienced variceal bleed. 